\title{
Call for Submissions
}

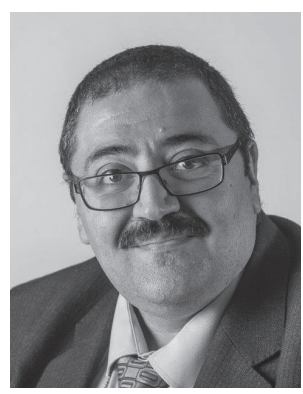

Abd Tahrani

Centre of Endocrinology, Diabetes and Metabolism, University of Birmingham, Birmingham, UK

DOI: https://doi.org/10.17925/EE.2017.13.02.49

Dear Colleagues

European Endocrinology would like to welcome members of the endocrinology community to contribute articles to the 2018 Spring edition. The journal is dedicated to publishing articles that provide practical guidance and advice on topical issues, to help physicians in their day-to-day clinical practice.

We encourage authors to submit original research, review articles and editorials across all areas of diabetes, obesity and endocrinology for consideration. We are particularly interested in reports of real-world studies, along with concise review articles to summarise the latest clinical trial data and developments in the field. Authors can submit their manuscript through the Editorial Manager portal (details below) and the journal's editor is pleased to receive pre-submission enquiries. Accepted articles are published open access both in print and online, and authors have the opportunity to publish accompanying multimedia content.

We look forward to working with you.

Abd Tahrani (Editor-in-Chief) and the European Endocrinology Team

Submissions Website: www.editorialmanager.com/touchendocrinology

Contact the Editor: nicola.cartridge@touchmedicalmedia.com

About the Journal: www.touchendocrinology.com/about-us

Instructions for Author: www.touchendocrinology.com/content/endocrinology-journals\#aims-and-scope

Citation: European Endocrinology, 2017;13(2):49 